\title{
Vaginal Misoprostol Prior to Intrauterine Contraceptive Device Insertion in Women Who Delivered Only By Elective Caesarean Section : Randomized Clinical Trial
}

\section{Original Article}

\author{
Noha A. Sakna, Magdy Mohamed Mahmoud Abd El-Gawad, Enas Mahmoud \\ Mohammed Mohammed Elshahid, Ahmed Atik
}

Department of Obstetrics and Gynecology, Faculty of Medicine, Ain-Shams University, Cairo

\begin{abstract}
Background: Intrauterine contraceptive devices (IUCDs) are one of the reversible effective contraceptives. However its use is limited by the high cost in some settings and fear of pain at insertion time. For healthcare professionals the obstacles to its use include lack of training, fear of causing pain with the procedure and difficulties during the procedure that could end in insertion failure.

Aim: The aim of the study was to evaluate the role of vaginal misoprostol (400microgram) administration $3 \mathrm{~h}$ prior to intrauterine contraceptive device (IUCD) insertion in women delivered only by elective caesarean section.

Materials and Methods: A double-blind randomized controlled trial was conducted in 210 women who were eligible for IUD insertion. Participants were randomly divided to receive either 400 microgram vaginal misoprostol or placebo $3 \mathrm{~h}$ before IUD insertion. The primary outcome measure was insertion difficulty score. Secondary outcome measures were the pain score during the procedure, complications of IUD insertion and side effects related to misoprostol.

Results: Insertion difficulty and pain scores were significantly lower in the misoprostol group compared with the placebo group (89 [84.8\%] vs. 41 [39.0\%]; $p<0.001$ and $1.3 \pm 0.6$ vs. $2.5 \pm 1.2 ; p<0.001$, respectively). More women experienced nausea, vomiting $(10$ vs. $0 ; p<0.001)$ and shivering $(6$ vs. $0 ; p<0.029)$ in the misoprostol group than in the placebo group, respectively.

Conclusion: The study concluded that using of misoprostol at a dose of 400 microgram administered vaginally 3 hours prior to IUCD insertion in women who delivered only by elective cesarean section had significant effect on increase easiness of insertion and reduce the incidence of pain during the procedure.
\end{abstract}

Key Words: CS, intrauterine contraceptive devices, misoprostol, pain

Received: 19 March 2020, Accepted: 24 August 2020

Corresponding Author: Noha A. Sakna, Department of Obstetrics and Gynecology, Faculty of Medicine, Ain-Shams University, Cairo Tel.: 01221065031,E-mail: nohasakna@gmail.com

ISSN: 2090-7265, February 2021, Vol.11, No. 1

\section{INTRODUCTION}

Intrauterine contraceptive devices (IUCDs) are one of the reversible effective contraceptives ${ }^{[1]}$.

However, its use is limited by the high cost in some settings and fear of pain at insertion time. For healthcare professionals, the obstacles to its use include lack of training, fear of causing pain with the procedure and difficulties during the procedure that could end in insertion failure $^{[2]}$.

Many healthcare professionals believe that failure or difficulty of insertion is common in adolescents and nulligravidas and this is one of the reasons that restrict IUCD use, despite the evidence and recommendations supporting use in these groups ${ }^{[3]}$.
Most IUCD insertions do not require pain control; however, a proportion of nulliparous $(17 \%)$ and multiparous $(11 \%)$ women experience significant pain and will require active pain management ${ }^{[2]}$.

Misoprostol is an inexpensive prostaglandin E1 analogue, which is associated with few side-effects ${ }^{[4]}$ and has been used extensively for its cervical softening effect before induction of labour and surgical evacuation of the uterus ${ }^{[5]}$, as it reduces the force required for cervical dilatation $^{[6]}$.

\section{AIM OF THE WORK}

The aim of study was to evaluate the role of vaginal Misoprostol $(400 \mathrm{mcg})$ administration $3 \mathrm{~h}$ prior to IUCD insertion in women delivered only by elective caesarean section. 


\section{PATIENTS AND METHODS}

Study Design: Double blinded placebo randomized controlled clinical trial.

Place: The study was conducted at family planning clinic of Ain-Shams University Maternity Hospital.

Population of study: Two hundreds and ten women candidates for IUCD insertion were enrolled in the study; group A received 400 microgram of misoprostol vaginally 3 hours before IUCD insertion and group B received placebo.

\section{Inclusion Criteria:}

All women were 20 to 40 years of age. Desired IUCD placement and were able to participate, negative pregnancy test, follow- up in 6-8 weeks for a standard IUCD follow-up visit and delivered only by elective cesarean section.

\section{Exclusion Criteria:}

Active cervical infection, current pregnancy, uterine anomaly, fibroid uterus, copper allergy/Wilson's disease. Undiagnosed abnormal uterine bleeding, cervical or uterine cancer, allergy to misoprostol and previous vaginal delivery.

Randomization was done using computer generated randomization programe.

\section{Allocation and concealment:}

Two hundreds and ten opaque envelopes were numbered serially and in each envelope the corresponding letter which denoted the allocated group was put according to randomization table then all envelopes were closed and put in one box. When the first patient arrived the first envelope was opened and the patient was allocated according to the letter inside.

\section{Interventions:}

1- Insertion of IUCD was done from the third day to the fifth day during the menstrual cycle.

2- Ultrasound was used prior to insertion to detect uterine position (Anteverted or Retroverted) and any intracavitary pathology (uterine anomaly and fibroid uterus) and also after insertion to detect IUCD is in place or not.

3- Participants were randomly allocated to either the misoprostol or placebo group guided by a computergenerated randomization list and both participants and observer didn't know which one received misoprostol and which received placebo.

4- Participants didn't receive any analgesics 24 hours before IUCD insertion.
5- Withdrawal technique was used for IUCD insertion.

6- $\mathrm{T} \mathrm{Cu}$ 380A was used in this study (PREGNA, Egemen international).

7- Assistant lecturer of family planning clinic inserted the IUCD.

8- Follow up in 6-8 weeks for a standard IUCD follow-up visit.

\section{Steps of IUCD insertion:}

Steps of the IUCD insertion procedure were explained to the client. Bimanual examination to determine the size, shape, and position of the uterus was done. A warm, moistened speculum was inserted. The cervix was cleaned with an antiseptic solution (Betadine) using 3 scopettes or more (one for each sweep of the cervix). The sterile insertion instruments were opened without touching the inside of the packet and placed within easy reach. The tenaculum was removed by its handle, grasped the anterior or posterior lip of the cervix and closed gently to the first notch having the client cough while the tenaculum was being attached. Gentle traction with the tenaculum to straighten the canal was applied.

The sound was removed by its handle and gently inserted to measure the depth of the uterus. Once the sound was inserted and removed, the depth of the uterine cavity was noted. IUCD pack was opened without touching its contents. Sterile gloves were put on. The IUCD was loaded and inserted into the uterine cavity according to the manufacturer instructions. The tenaculum was gently removed tamponade any bleeding from the tenaculum site until resolving. The strings of the IUCD were trimmed to $3-4 \mathrm{~cm}$ in length.

\section{STATISTICAL ANALYSIS:}

The collected data were coded, tabulated and statistically analyzed using IBM SPSS statistics (Statistical Package for Social Sciences) software version 18.0, IBM Corp., Chicago, USA, 2009. Descriptive statistics were done for quantitative data as minimum\& maximum of the range as well as mean $\pm \mathrm{SD}$ (standard deviation) for quantitative normally distributed data, while it was done for qualitative data as number and percentage. Inferential analyses were done for quantitative variables using Shapiro-Wilk test for normality testing, independent t-test in cases of two independent groups with normally distributed data. In qualitative data, inferential analyses for independent variables were done using Chi square test for differences between proportions and Fisher's Exact test for variables with small expected numbers. The level of significance was taken at $P$ value $<0.050$ is significant, otherwise is non-significant. 


\section{Intervention values were calculated as follows:}

Rate elevation=Study Rate - Control Rate. Efficacy= (Study Rate - Control Rate) / Study rate

Relative Rate $=$ Study Rate $/$ Control Rate. Number needed to treat $=1 /$ (Study Rate - Control Rate)

\section{RESULTS}

No significant differences between the studied groups regarding age, BMI, parity and uterine position (Table 1).

Table 2 showed that insertion was significantly easier among Misoprostol group.
Table 3 showed that pain perception was significantly lower among Misoprostol group than among control group.

Table 4 showed that nausea and vomiting and shivering were significantly more frequent among Misoprostol group.

Satisfaction was significantly more frequent among Misoprostol group while insertion complications were non-significantly less frequent among Misoprostol group.

Table 5 showed that no significant difference between the studied groups regarding expulsion within 8 weeks.

Table 1: Demographic characteristics among the studied groups

\begin{tabular}{|c|c|c|c|c|}
\hline Items & Measure & Misoprostol $(\mathrm{N}=105)$ & Control $(\mathrm{N}=105)$ & $P$ \\
\hline \multirow[t]{3}{*}{ Age (years) } & Mean \pm SD & $30.6 \pm 6.2$ & $30.6 \pm 5.8$ & \multirow{3}{*}{$\wedge 0.963$} \\
\hline & & & & \\
\hline & Range & $20.0-40.0$ & $21.0-40.0$ & \\
\hline \multirow[t]{3}{*}{ BMI (kg/m2) } & Mean \pm SD & $29.7 \pm 4.2$ & $29.0 \pm 4.5$ & \multirow{3}{*}{$\wedge 0.229$} \\
\hline & & & & \\
\hline & Range & $21.4-37.4$ & $20.8-37.4$ & \\
\hline \multirow[t]{3}{*}{ Parity } & $\operatorname{Median}\left(1^{\text {st }}-3^{\text {rd }} \mathrm{IQ}\right)$ & $3.0(2.0-4.0)$ & $3.0(2.0-4.0)$ & \multirow{3}{*}{$\S 0.388$} \\
\hline & & & & \\
\hline & Range & $1.0-6.0$ & $1.0-5.0$ & \\
\hline \multirow[t]{2}{*}{ Uterine position (n, \%) } & AVF & $87(82.9 \%)$ & $88(83.8 \%)$ & \multirow[b]{2}{*}{ \# 0.853} \\
\hline & RVF & $18(17.1 \%)$ & $17(16.2 \%)$ & \\
\hline
\end{tabular}

IQ: Inter-quartiles. ^Independent t-test. \#Chi square test. §Mann Whitney test 
Table 2: Ease of insertion among the studied groups

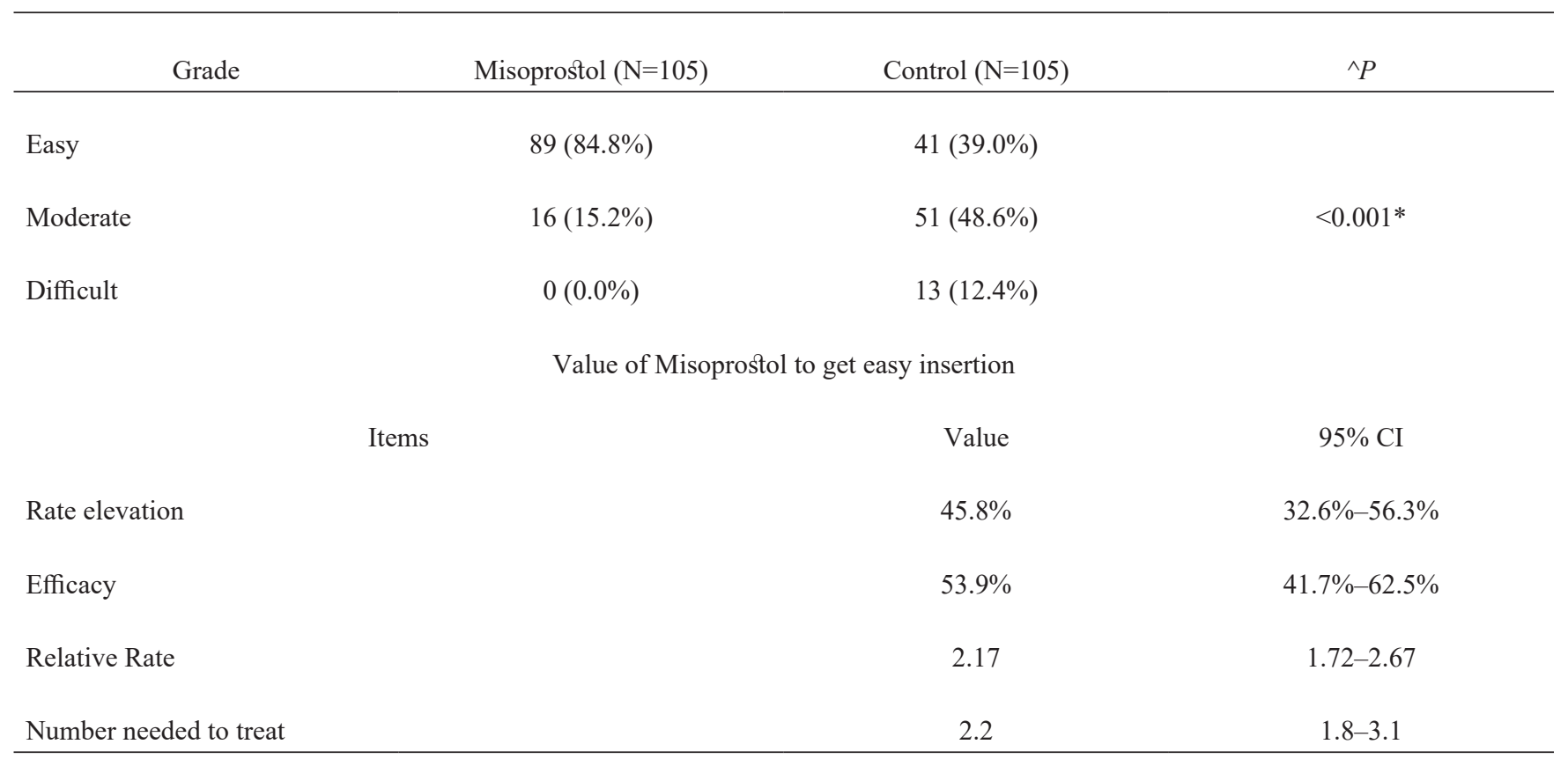

${ }^{\wedge}$ Chi square test. *Significant, CI: Confidence interval

Table 3: Pain perception (VAS-10) among the studied groups

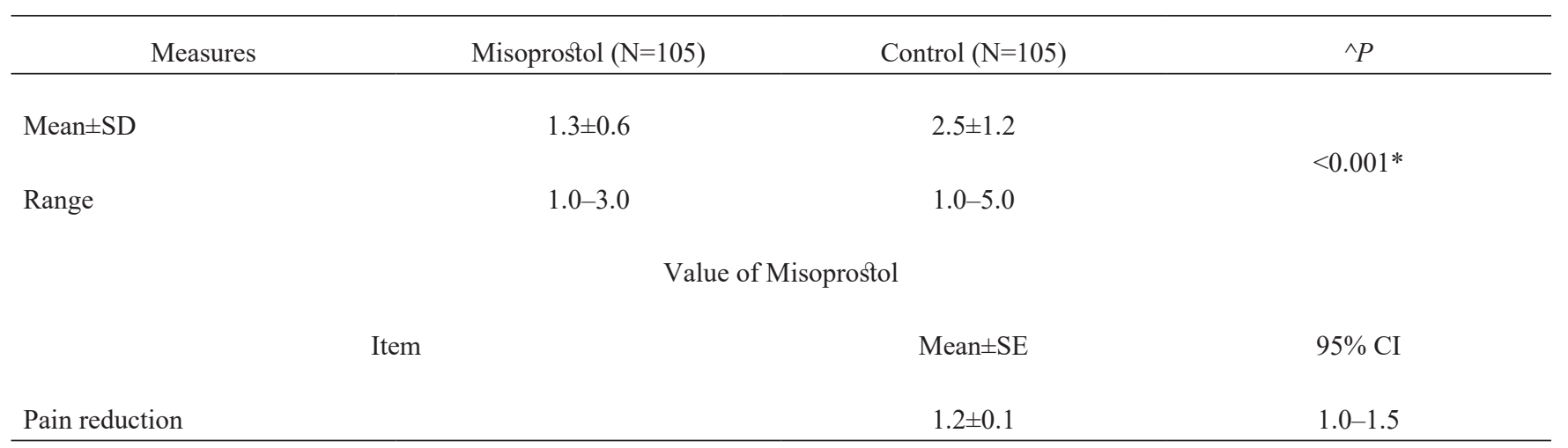

Independent t-test, CI: Confidence interval, *Significant 
Table 4: Misoprostol side effects, insertion complications and satisfaction among the studied groups

\begin{tabular}{|c|c|c|c|c|}
\hline Characteristic & Misoprostol (N=105) & Control $(\mathrm{N}=105)$ & $P$ & $\mathrm{RR}(95 \% \mathrm{CI})$ \\
\hline Bradycardia & $8(7.6 \%)$ & $4(3.8 \%)$ & $\wedge 0.234$ & $2.00(0.62-6.44)$ \\
\hline Nausea\& vomiting & $10(9.5 \%)$ & $0(0.0 \%)$ & $\wedge^{\wedge} 0.001 *$ & -- \\
\hline Shivering & $6(5.7 \%)$ & $0(0.0 \%)$ & $\# 0.029 *$ & -- \\
\hline Rash & $0(0.0 \%)$ & $0(0.0 \%)$ & -- & -- \\
\hline Diarrhea & $0(0.0 \%)$ & $0(0.0 \%)$ & -- & -- \\
\hline Fever & $0(0.0 \%)$ & $0(0.0 \%)$ & -- & -- \\
\hline Syncope & $0(0.0 \%)$ & $0(0.0 \%)$ & -- & -- \\
\hline Moderate bleeding & $10(9.5 \%)$ & $14(13.3 \%)$ & ${ }^{\wedge} 0.386$ & $0.71(0.33-1.54)$ \\
\hline Insertion failure & $0(0.0 \%)$ & $4(3.8 \%)$ & $\# 0.121$ & -- \\
\hline Perforation & $0(0.0 \%)$ & $2(1.9 \%)$ & $\# 0.498$ & -- \\
\hline Women satisfaction & $97(92.4 \%)$ & $67(63.8 \%)$ & $<0.001^{*}$ & $1.45(1.25-1.61)$ \\
\hline
\end{tabular}

Chi square test. \#Fisher's Exact test.

Table 5: Expulsion within 8 weeks among the studied groups

\begin{tabular}{lcccc}
\hline Expulsion & Misoprostol $(\mathrm{N}=105)$ & Control $(\mathrm{N}=105)$ & \#P & RR (95\% CI) \\
\hline Partial expulsion & $4(3.8 \%)$ & $3(2.9 \%)$ & 1.000 & $1.33(0.31-5.81)$ \\
No expulsion & $101(96.2 \%)$ & $102(97.1 \%)$ & & \\
\hline
\end{tabular}

\#Fisher's Exact test. RR: Relative rate, *Significant, CI: Confidence interval 


\section{DISCUSSION}

IUCD has been used for a long duration; it is a highly effective method, with a high degree of user satisfaction and leaves little room for user error, making it the perfect method for females seeking contraception $^{[7]}$.

In one study, among women choosing copper IUCDs for emergency contraception, the data revealed a higher number of unsuccessful insertions than expected. Most notably, $17.6 \%$ of women electing to receive the IUCD for emergency contraception failed to have an IUCD inserted that day. The data from this study demonstrate a much higher rate of unsuccessful insertions than previously reported in the literature ${ }^{[8]}$.

One hypothesis is that patient anxiety has an increased incidence of complications or failure. Another hypothesis is cervical spasm. Risk factors for cervical spasm were not correctly studied. However, postmenopausal women are more likely to require cervical dilatation, and breastfeeding women are less likely to require cervical dilatation ${ }^{[9]}$.

Misoprostol has not been studied as rigorously in nonpregnant women, a systematic review of its use before hysteroscopy demonstrated a reduced need for cervical dilation and a reduced incidence of cervical laceration compared with placebo while noting a greater incidence of side effects ${ }^{[10]}$.

In one study aiming to determine whether preoperative cervical preparation by misoprostol facilitates cervical dilatation during operative hysteroscopy there was moderate quality evidence that use of misoprostol for preoperative ripening of the cervix before operative hysteroscopy is more effective than placebo or no treatment ${ }^{[11]}$.

Two experimental trials using prostaglandin (PGf $2 \alpha$ or misoprostol) before IUCD insertion have shown that IUCD insertion was easier ${ }^{[12]}$.

Among the studies of prostaglandin use for IUCD insertion, all have noted an increase in pain and/or side effects with treatment ${ }^{[13]}$ and in one case series of patients with a failed IUCD insertion attempt, all had a successful IUCD insertion 1 day after being treated with misoprostol.

While three additional experimental trials for IUCD insertion failed to show a significant difference in the ease of insertion between the treatment and control $\operatorname{groups}^{[14,15,16]}$.

The main aim of this study was to investigate a possible effect of vaginal administration of misoprostol prior to insertion of IUCDs in women delivered only by elective caesarean section.

This study was conducted in Ain-Shams University Maternity Hospital on 210 women, 105 women (group A) were given two tablet of $200 \mathrm{mcg}$ misoprostol vaginally 3 hours before the IUCD insertion and the other 105 women (group B) received placebo vaginally 3 hours before the IUCD insertion.

The current study showed that there was no statistically significant difference between both groups as regard general demographic data including age and BMI.

In the present study, the mean age of patients in both groups was 30.6 with a standard deviation \pm 6.2 . Regarding BMI, the mean BMI for both groups was 29.7 with a $\mathrm{SD} \pm 4.2$.

In Abdellah ${ }^{[17]}$, the mean age for the two groups was $28.1 \pm 6$, while the mean BMI for the two groups was $26.9 \pm 5.3$

This study showed that there was no statistically significant difference between both groups as regard parity and uterine position; that was similar to the finding in ${ }^{[17,18]}$.

In the present study, there was no statistically significant difference between the two groups according to parity $(P$ value $=0.38)$, while in Abdellah ${ }^{[17]}$ ( $P$ value $=0.65)$. Also, there is no significant difference between the two groups according to uterine position $(P$ value $=0.853)$ while in Rasheedy ${ }^{[18]}$ $(P$ value $=0.502)$.

In the current study, there was a high statistically significant difference between the two groups according to the easiness of insertion with a $P$ value $<0.001$.

The present study results were in agreement with Maged ${ }^{[19]}$ who showed that there was a significant difference between the two groups with less difficulty in inserting the IUCD $(P$ value $<0.001)$ in the group that was given misoprostol compared to the group that received placebo.

In the current study, there was a highly statistically significant difference between the two groups according to pain perception via VAS with a $P$ value $<0.001$

The present study results were in agreement with Abdellah $^{[17]}$ who showed that there was a significant difference between the two groups according to pain perception via VAS $(P$ value $<0.001)$ and 
Maged $^{[19]}(P$ value $<0.001)$ in the group that was given misoprostol compared to the group that received placebo.

In the current study, satisfaction was significantly more frequent among misoprostol group with $P$ value $<0.001$. This is in agreement with Abdellah $^{[17]}$ with $P$ value $<0.001$ for women satisfaction among the two groups.

In the current study, insertion complications like bleeding, insertion failure and perforation showed non-significant difference between the two groups with $(P$ value $>0.05)$, this is in agreement with Maged $^{[19]}$ and Adriana ${ }^{[20]}$ with $(P$ value $>0.05)$.

In the current study, nausea, vomiting and shivering were significantly more frequent among misoprostol group but benefits overweight side effects of misoprostol; this is in agreement with Abdellah ${ }^{[17]}$ for shivering with $(P$ value $=0.001)$.

In the current study, no significant difference between the studied groups regarding expulsion within 8 weeks partial expulsion in misoprostol was 4 out of 105 while in placebo group was 3 out of 105 .

On the other hand, the results didn't agree with some studies which found that misoprostol was not useful to facilitate the insertion of IUCDs. However, most of these previous studies have been carried out with nulliparous women whereas in the present study women were selected among those with elective cesarean sections.

Espey $^{[21]}$ showed that there was no difference in pain score during IUCD insertion in women received pre-insertion misoprostol or placebo and also no differences in investigator perception of ease of insertion.

Also, there were no differences in side effects including fever, nausea, vomiting or diarrhea between women who received misoprostol versus who received placebo.

Lathrop $^{[22]}$ showed that misoprostol did not decrease investigator perception of ease of insertion of IUCD in nulliparous women. There was no difference in difficulty between the misoprostol group and the placebo group as the perception of ease was not improved with the addition of misoprostol.

It also showed that misoprostol did not decrease patient's reported pain with insertion; patients in the misoprostol group experienced an increase in pain at the 3 pain measurement points (just prior to IUD insertion, just after insertion and prior to discharge from the clinic) placebo group. After misoprostol administration compared to the Edelman ${ }^{[23]}$ showed that no significant difference in pain felt by participant with $P$ value $=0.83$.

Also, investigator reported easy insertion in both groups. So, the present study have proven that vaginal administration of two tablet of $200 \mathrm{mcg}$ misoprostol 3 hours prior to IUCD insertion in women delivered only with elective caesarean sections has a significant effect in improve easiness of insertion and decrease pain felt by participants.

The intrauterine contraceptive device (IUCD) is a safe, extremely effective and long acting reversible contraceptive (LARC) method. It is possible that difficulty in inserting the device limits its use.

Until a short time ago, the IUCD was indicated only for multiparas this recommendation probably originating from misgivings regarding a possible increase in the incidence of acute PID and the association between this condition and infertility. Although, all subsequent studies have confirmed that this risk is low.

In an attempt to improve the ease of IUCD insertion, the current study tested the use of misoprostol prior to the insertion.

Two hundreds and ten women delivered only with elective caesarean sections are candidate for $\mathrm{T} \mathrm{Cu}$ 380A IUCD insertion participated in the study. Half of them were given 400 microgram of misoprostol vaginally and the other half was given the placebo (Starch tablets).

This study was conducted in Ain-Shams University Maternity hospital during the period from October 2018 to June 2019 by blinded placebo randomized controlled clinical trial.

\section{Inclusion Criteria:}

All women were 20 to 40 years of age. Desired IUCD placement and were able to participate. Negative pregnancy test, follow- up in 6-8 weeks for a standard IUCD follow-up visit as well as delivered only by elective cesarean section.

\section{Exclusion Criteria:}

Active cervical infection, current pregnancy, uterine anomaly, fibroid uterus, copper allergy/Wilson's 
disease, undiagnosed abnormal uterine bleeding, cervical or uterine cancer, and allergy to misoprostol as well as previous vaginal delivery.

\section{Study outcome measures: Primary outcomes:}

The outcome measure of this study was the proportion of failed IUCD insertions regardless of the reason (e.g. immediate expulsion or impossibility to sound the uterus or any resistance or need for dilatation was recorded). The degree of difficulty of the IUCD insertion judged as the resistance of the internal cervical so experienced by the investigator.

\section{Secondary outcome:}

Reducing pain intensity during IUCD also would have been measured by visual analogue scale ranging from $0-10$ according to pain intensity: (0) means no pain and (10) means worst possible pain. The present study has proven that vaginal administration of two tablet of $200 \mathrm{mcg}$ misoprostol 3 hours prior to IUCD insertion in women delivered only with elective caesarean sections has a significant effect in improve easiness of insertion and decrease pain felt by participants Among the included women, administration of misoprostol prior to IUCD insertion was significantly associated with almost 2 folds increase in the success rate of IUCD insertion. 89 out of 105 patients of group A who received misoprostol had successful easy insertion while in group B who received placebo only 41 out of 105 patients had successful easy insertion.

\section{CONCLUSION}

The study concluded that using of misoprostol at a dose of 400 microgram administered vaginally 3 hours prior to IUCD insertion in women who delivered only by elective cesarean section had significant effect on increase easiness of insertion and reduce the incidence of pain during the procedure.

\section{CONFLICT OF INTEREST}

There are no conflicts of interests.

\section{REFERENCES}

1. Bahamondes L, Bottura BF, Bahamondes MV, Goncalves MP, Correia VM, Espejo-rce X, Sousa MH, Monteiro I, Fernandes A (2014): Estimated disability adjusted life years averted by longterm provision of long acting Contraceptive methods in a Brazilian clinic. Human Reproduction; 29:2163-2170.

2. Marions L, Lovkist L, Taube A, Johansson M, Dalvik H, Overlie SI (2011): Use of the levonorgestrel releasing-intrauterine system in nulliparous women - a non-interventional study in Sweden. European Journal of Contraception and Reproductive Health Care; 16(2):126-134.

3. Berenson AB, Tan A, Hirth JM, Wilkinson GS (2013): Complications and continuation of intrauterine device use among commercially insured teenagers. International Journal of Obstetrics and Gynecology; 121:951-958.

4. Wing DA and Gaffaney CA (2006): Vaginal misoprostol administration for cervical ripening and labor induction. Clinical Obstetrics and Gynecology; 49(3):627-641.

5. Aronsson A, Marions L (2007): Cervical priming with sublingual misoprostol prior to insertion of an intrauterine device in nulliparous women: a randomized controlled trial. Human Reproduction, 22:2647-2652.

6. Cleary B (2010): Misoprostol Pharmacokinetics and Pharmaco dynamics International Journal of Obstetrics and Gynaecology;96 (4): 265-272.

7. Hatcher RA, Truss ell JA, Nelson AL, Gates W, Stewart FH, Kowal D (2007): Contraceptive Technology, 19 revised edition. New York: Ardent Media; 117-119.

8. Amna ID, David KT, Janet CJ, Marie ESF, Molly M, Kathy B (2003): Failed IUD insertions in community practice: an under-recognized problem Contraception. 87(2): 182-186.

9. Miranda F and Anne W (2003): Intrauterine device insertion-related complications: can they be predicted? Journal of Family Planning and Reproductive Health Care; 29: 227-231.

10. Crane JM and Healey S (2004): Use of misoprostol before hysteroscopy: a systematic review. Journal of Obstetrics and Gynaecology Canada; 28:373-379.

11. Al-Fozan H, Firwana B, Al Kadri H, Hassan S, Tulandi T (2015): Preoperative ripening of the cervix before operative hysteroscopy. Cochrane Database Systematic Review ; (4): article number CD005998.

12. Saav I, Aronsson A, Marions L, Stephansson O, Gemzell-Danielsson K(2007): Cervical 
priming with sublingual misoprostol prior to insertion of an intrauterine device in nulliparous women: a randomized controlled trial. Human Reproduction;22:2647-2652.

13. Ward K, Jacobson JC, Turok DK, Murphy PA (2011): A survey of provider experience with misoprostol to facilitate intrauterine device insertion in nulliparous women. Contraception; 84:594-599

14. Heikinheimo $\mathrm{O}$, Inki $\mathrm{P}$, Kunz $\mathrm{M}$, Parmhed $\mathrm{S}$, Anttila AM, Olsson SE, Hurskainen R, GemzellDanielsson K(2011): Double-blind, randomized, placebo-controlled study on the effect of misoprostol on ease of consecutive insertion of the levonorgestrel-releasing intrauterine system. Contraception ;81:481-486.

15. Schaefer E, Van Houten L, Olson A, Leclair C, Bednarek PH, Edelman A(2010): Prophylactic misoprostol prior to IUD insertion in nulliparous women. Contraception;82:188.

16. Dijkhuizen K, Dekkers OM, Holleboom CA, de Groot CJ, Hellebrekers BW, van Roosmalen GJ, Janssen CA, Helmerhorst FM. (2011): Vaginal misoprostol prior to insertion of an intrauterine device: an RCT. Human Reproduction; 26:323-329.

17. Abdellah MS, Abbas AM, Hegazy AM(2017): Vaginal misoprostol prior to intrauterine device insertion in women delivered only by elective cesarean section: a randomized double-blind clinical trial. Contraception;95:538-543.

18. Rasheedy R, Tamara TF, Allam IS, Abbas AM,
Abdel Salam NEE, Ahmed AF (2019): Vaginal misoprostol before intrauterine contraceptive device insertion following previous insertion failure: randomized clinical trial: The European Journal of Contraception \& Reproductive Health Care; 24(3): 222-226.

19. Maged AM, Youssef G, Eldaly A, Omran E, El Naggar M, Abdel Hak A, Kotb A, Ogila AI (2018): Benefits of vaginal misoprostol prior to IUD insertion in women with previous caesarean delivery: a randomised controlled trial. European Journal of Contraception and Reproductive Health Care;23(1):32-37.

20. Adriana S, Alex SRS, Aurélio ARC, Melania MRA (2013): Misoprostol prior to inserting an intrauterine contraceptive device in nulligravidas: a randomized clinical trial Human Reproduction, Vol.28, No.8 pp. 2118-2125.

21. Espey E, Singh RH, Leeman L, Ogburn T, Fowler K, Greene H (2014): Misoprostol for intrauterine device insertion in nulliparous women: arandomized controlled trial. American Journal of Obstetrics and Gynecology; 210(3):208.e1-208.e5.

22. Lathrop E, Haddad L, McWhorter CP, Goedken P (2013): Self-administration of misoprostol prior to intrauterine device insertion among nulliparous women; 88(6):725-729.

23. Edelman AB, Schaefer E, Olson A, Van Houten L, Bednarek P, Leclair C, Jensen JT(2011); Effects of prophylactic misoprostol administration prior to intrauterine device insertion in nulliparous women. Contraception 2011; 84:234-239. 